\title{
Die Gemäldesammlung des griechischen Patriarchats in Kairo.
}

Das Museum der geistlichen Akademie zu Kiew besitzt zwei Ikonen ${ }^{1}$ ), welche in jener enkaustischen Technik ausgeführt sind, die heute an den neuerdings im Fajum gefundenen Mumienporträts so sehr bewundert wird. $\mathrm{Da}$ auch sie aus Ägypten und zwar vom Sinai stammen, liefs sich hoffen, dafs das Nilland noch mehr derartige Schätze liefern würde. Der Unterzeichnete war daher sehr erfreut, als ihm vor Antritt der Reise ein Aufsatz von Mazaraki²) bekannt wurde, worin die Gemälde eines Klosters bei Kairo katalogisiert und unter ca. 65 Nummern nicht weniger als 23 (21) aufgeführt werden, die älter als das 7. Jahrhundert seien, und eine ganze Reihe, worunter ein grofser Zyklus von Darstellungen aus dem Leben Christi, die dem 7. Jahrhundert selbst angehören sollten. $\mathrm{Da}$ nun. die Gemälde vom Sinai wahrscheinlich dem 7. Jahrhundert etwa entstammen, liefs sich erwarten, dafs die von Mazaraki beschriebenen Gemälde in derselben Technik ausgeführt und vom höchsten Werte sein würden.

Was die Erwartungen noch steigerte, ist, dafs das Kloster, in dem sich die Gemälde befinden sollten, thatsächlich an derjenigen Stelle steht, die als die älteste Ansiedlung auf der Stelle des heutigen Kairo golten mufs. Amr, der Eroberer Ägyptens, gründete sein Fostat in der Nähe einer römisch-byzantinischen Festung, deren Mauern und Türme heute noch teilweise aufrecht stehen. Sie fallen jedem ins Auge, der die Bahn nach Altkairo oder Heluan benutzt. Die Station S. Georges liegt dicht dabei. Der Name derselben bezeichnet zugleich das alte griechische Kloster, welches auf einem der Festungstürme erbaut ist und neuerdings in das griechische Kranken- und Armenhaus von Kairo umgewandelt wurde. Die Kirche dieses Gebäudes nun enthielt einst die Sammlung, welche Mazaraki beschreibt. Der Unterzeichnete fand nur noch einige Ikonen der kretischen Schule vor, so

1) Abg. Byz. Denkmäler I Taf. VIII.

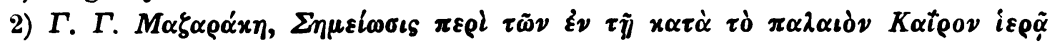

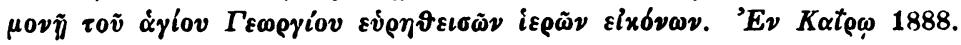


eine Hodegetria von der Hand des Angelos Kres 1604, einen Pantokrator von 1798 und einen hl. Sabbas von 1799, beide von der Hand des Neophytos Kres, endlich eine Mutter Gottes í 'A $\mu$ ódvvvos von Jeremias Kres. Alle übrigen älteren Bilder seien, hiefs es, nach dem Patriarchat in Kairo gebracht worden.

In der Thür dieses sog. Museums im Kairiner Patriarchate nun endete der langgehegte Traum von dem Schatze alter enkaustischer Bilder. Ein Blick auf die in einem kleinen Saale auf Regalen längs der Wände aufgestellten Tafeln genügte. Altersgrau war daran nur der Staub und der elende Zustand. Der grölste Teil der Tafeln ist beschädigt oder bis zur Unkenntlichkeit verblafst. Was noch zu erkennen war, gehört, um es kurz zu sagen, dem 14. bis 17. Jahrhundert, ja zum Teil einer noch jüngeren Zeit an; nur einige wenige Stücke können älter sein, gehen aber keinesfalls über das 13. Jahrhundert heraus. Das interessanteste und vielleicht älteste Stück ist die Darstellung der Engelchöre, welche das Medaillon des Emmanuel halten (Maz. Nr. 11). Das stereotype $\mathrm{Zu}$ - und Abneigen der voll gebildeten Engelköpfe ist noch das gleiche wie im Jacobus Monachus der Vaticana und in Paris (vgl. Byz. Z. IV $109 \mathrm{ff}$.) und wie in den Madonnen des Cimabue. Mazaraki setzt das Bild vor das 7. Jahrhundert. Diesem selbst

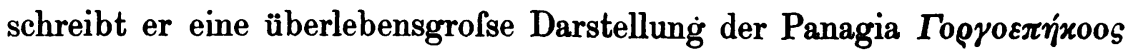
zu (Nr. 24), die teilweise bis auf die derben Umrifsskizzen zerstört ist, und eine Folge von 21 Darstellungen aus dem Leben Christi von der Verkündigung bis zum Tode Mariä (Nr. 26), beide etwa dem 15. Jahrhundert angehörig. Für die Kenntnis der bÿzantinischen Kunst kommt hier nicht viel heraus. Überhaupt zeigt sich Ägypten im allgemeinen nach dieser Richtung bei weitem weniger ergiebig, als man erwarten sollte; doch davon bei anderer Gelegenheit.

Kairo, Januar 1895.

Josef Strzygowski. 